\title{
CORRIGENDUM
}

\section{A defect in the CLIP1 gene (CLIP-170) can cause autosomal recessive intellectual disability}

Farzaneh Larti, Kimia Kahrizi, Luciana Musante, Hao Hu, Elahe Papari, Zohreh Fattahi, Niloofar Bazazzadegan, Zhe Liu, Mehdi Banan, Masoud Garshasbi, Thomas F Wienker, H Hilger Ropers, Niels Galjart and Hossein Najmabadi

European Journal of Human Genetics (2015) 23, 416; doi:10.1038/ejhg.2014.152

Correction to: European Journal of Human Genetics (2015) 23, 331-336; doi:10.1038/ejhg.2014.13; published online 26 February 2014

Upon revisiting their published work on a defect in the CLIP1 gene, the authors noted that the brain MRI obtained from the affected girl
(IV: 7), which was reported to be normal at that time, showed a local white matter around fornices with abnormal signal of the frontal horns' 'focal leukoencephalopathy'. They would like to report focal leukodystrophy in the brain MRI of the patient with CLIP1 mutation as a migration role of this gene in cortical neurons (Figure 1).

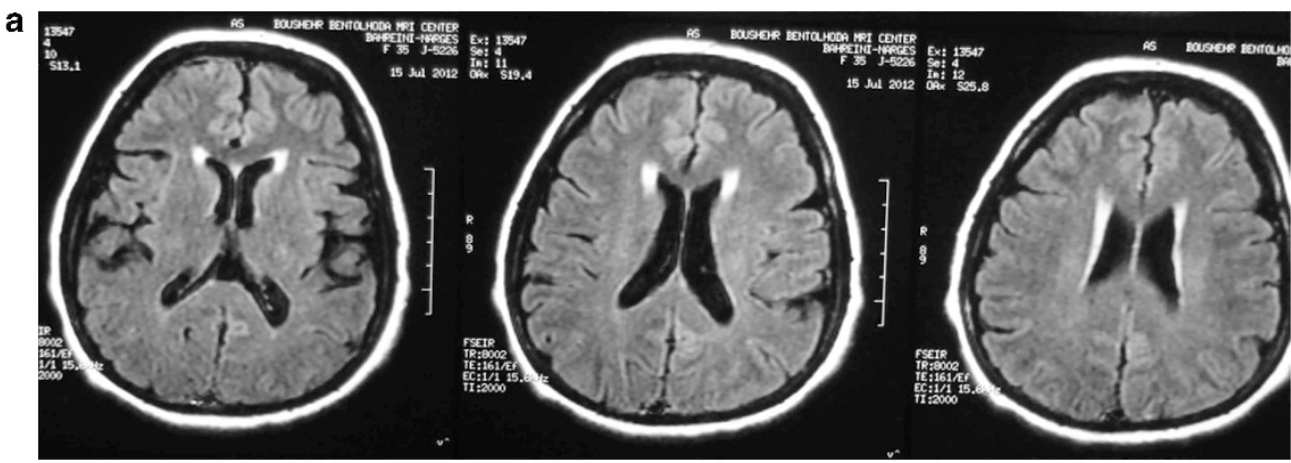

Figure 1 (a) Axial section of flair showed local white matter around fornices with abnormal signal of frontal horns 'focal leukodystrophy'. 